\title{
Correction to: Trends, variability and predictive skill of the ocean heat content in North Atlantic: an analysis with the EC-Earth3 model
}

\author{
Teresa Carmo-Costa ${ }^{1}\left[\right.$. Roberto Bilbao ${ }^{2} \cdot$ Pablo Ortega $^{2} \cdot$ Ana Teles-Machado $^{3} \cdot$ Emanuel Dutra $^{3}$
}

Published online: 29 November 2021

(c) The Author(s) 2021

\section{Correction to: Climate Dynamics \\ https://doi.org/10.1007/s00382-021-05962-y}

In the original publication of the article, there is correction in the acknowledge section. The new acknowledgement text could read as,

"We would like to acknowledge the financial support from the Spanish Ministry of Economy, Industry and Competitiveness via the grant RYC-2017-22772 (FSE/Agencia Estatal de Investigación) the FCT (Fundação para a Ciência e a Tecnologia) through projects FCT-UIDB/50019/2020 and $\mathrm{PD} / \mathrm{BD} / 142785 / 2018$, and the European Commission through the H2020 project EUCP. We also thank the two anonymous reviewers for their very positive and constructive feedback"
The original article has been corrected.

Publisher's Note Springer Nature remains neutral with regard to jurisdictional claims in published maps and institutional affiliations.

The original article can be found online at https://doi.org/10.1007/ s00382-021-05962-y.

Teresa Carmo-Costa

tmcosta@fc.ul.pt

1 Instituto Dom Luiz-Faculdade de Ciências da Universidade de Lisboa, Edificio C8, Campo Grande, 1749-016 Lisbon, Portugal

2 Barcelona Supercomputing Center, Barcelona, Spain

3 Instituto Dom Luiz, Instituto Português do Mar e da Atmosfera, Lisbon, Portugal 